firn and ice. The interpretation model yields the variation with surface-normal depth $\mathrm{z}$ of temperature $\mathrm{T}$, heat flux $\mathrm{q}$, ice pressure $p$, density $\rho$, surface-normal component of flow velocity $w$, down-slope component of flow velocity $u$, depositional age $t_{a}$, two-way wave travel time $\tau_{2}$, and twoway propagation loss $\mathrm{P}_{2}$. The following system of linear differential equations is integrated using the Runge-Kutta method:

$$
\frac{\mathrm{dT}}{\mathrm{dz}}=-\frac{\mathrm{q}}{\mathrm{K}}
$$

$\frac{\mathrm{dq}}{\mathrm{dz}}=-\mathrm{pcw} \frac{\mathrm{dT}}{\mathrm{dz}}+2 \mathrm{~B}_{0} \exp (-\mathrm{Q} / \mathrm{RT})(\mathrm{Fp} \tan \alpha)^{(\mathrm{n}+1)}+\frac{\mathrm{pw}}{3 \rho} \frac{\mathrm{d} \rho}{\mathrm{dz}}$

$\frac{\mathrm{dp}}{\mathrm{dz}}=\mathrm{pg} \cos \alpha$

$\frac{\mathrm{d} \rho}{\mathrm{dz}}=\mathrm{m}_{1} \rho^{2}\left(\frac{\rho_{\mathrm{I}}-\rho}{\rho_{\mathrm{I}}}\right) \quad \mathrm{p} \leqslant \mathrm{p}^{*}$

$$
=m_{2} \rho^{2}\left(\frac{\rho_{I}-\rho}{\rho_{I}}\right) \quad p>p^{*}
$$

$$
\frac{d w}{d z}=-\frac{w}{\rho} \frac{d \rho}{d z}-\Delta_{0}
$$

$\frac{\mathrm{du}}{\mathrm{dz}}=-2 \mathrm{~B}_{0} \quad \exp (-\mathrm{Q} / \mathrm{RT})(\mathrm{Fp} \tan \alpha)^{\mathrm{n}}$

$\frac{\mathrm{dt}_{\mathrm{a}}}{\mathrm{dz}}=\frac{1}{\mathrm{w}}$

$\frac{\mathrm{d} \tau}{\mathrm{dz}}=\frac{2 \sqrt{\epsilon}}{\mathrm{v}_{0}}$

$$
\frac{\mathrm{dP}_{2}}{\mathrm{dz}}=2 \mathrm{D}
$$

together with physical property relations such as the following

$$
\begin{aligned}
\mathrm{c}(\mathrm{T}) & =2115.343+7.7929\left(\mathrm{~T}-\mathrm{T}_{0}\right) \\
\mathrm{K}(\rho, \mathrm{T}) & =2 \rho \mathrm{K}_{\mathrm{I}}(\mathrm{T}) /\left(3 \rho_{\mathrm{I}}-\rho\right) \\
\mathrm{K}_{\mathrm{I}}(\mathrm{T})= & 2.1725-3.403 \times 10^{-3}\left(\mathrm{~T}-\mathrm{T}_{0}\right)+ \\
& \quad+9.085 \times 10^{-5}\left(\mathrm{~T}-\mathrm{T}_{0}\right)^{2} \\
\epsilon(\rho)= & \left(1+8.5 \times 10^{-4} \rho\right)^{2} \\
\mathrm{D}(\mathrm{T})= & \mathrm{D}_{0} \exp (-\mathrm{E} / \mathrm{RT}) .
\end{aligned}
$$

The boundary conditions on the integration variables are $\mathrm{T}(0)=\mathrm{T}_{\mathrm{S}}, \mathrm{T}(\mathrm{h})=\mathrm{T}_{\mathrm{M}}, \mathrm{p}(0)=0, \rho(0)=\rho_{\mathrm{S}}, \mathrm{w}(0)=\mathrm{w}_{\mathrm{s}}, \mathrm{u}(\mathrm{h})$ $=u_{B}, t_{a}(0)=0, \tau_{2}(0)=0$, and $P_{2}(0)=0$, where $T_{S}$ is surface temperature, $T_{M}$ is bottom temperature, $\rho_{S}$ is surface density, $w_{s}$ is surface-normal velocity measured at the glacier surface, and $u_{B}$ is sliding velocity. The remaining variables are thermal conductivity $\mathrm{K}$, specific heat capacity c, flow-law constant $B_{0}$, creep activation energy $Q$, universal gas constant $R$, shape factor $F$, surface slope $\alpha$, flow-law exponent $\mathrm{n}$, gravity acceleration $\mathrm{g}$, empirical constants $\mathrm{m}_{1}, \mathrm{~m}_{2}$, and $\mathrm{p}^{*}$ from Benson's firn-densification law (Benson C S 1962 Stratigraphic studies in the snow and firn of the Greenland ice sheet. SIPRE Research Report $70)$, ice density $\rho_{\mathrm{I}}$, surface value of two-dimensional flow divergence $\Delta_{0}=(\partial \mathrm{u} / \partial \mathrm{x}+\partial \mathrm{v} / \partial \mathrm{y}) \mathrm{s}$, relative dielectric permittivity $\epsilon$, free-space electromagnetic wave velocity $v_{0}$, propagation loss rate $\mathrm{D}, \mathrm{T}_{0}=273.16^{8} \mathrm{~K}$, thermal conductivity of ice $K_{1}$, loss-law constant $D_{0}$, and activation energy for propagation loss $\mathrm{E}$. The units of temperature and density in the above equations are respectively $\mathrm{K}^{\circ}$ and $\mathrm{kg} \mathrm{m}^{-3}$.

Preliminary modelling has yielded an age-depth relationship for internal reflecting layers that roughly matches the known eruption record for Mount Wrangell and extends the volcanic history by more than 200 years. High signal absorption rates restrict interpretation of the caldera geometry. Reflections from the bed are not consistently detectable beyond a depth of approximately $350 \mathrm{~m}$, suggesting a loss rate of $7-8 \mathrm{~dB}$ per $100 \mathrm{~m}$ of path length. The anomalous losses are attributed to abnormally high concentrations of ionic impurities and scattering sources.

\title{
INTERPOLATION TECHNIQUES FOR THE DISPLAY OF REMOTELY SENSED GLACIOLOGICAL DATA
}

\author{
(Abstract) \\ by
}

A.P.R. Cooper

(Scott Polar Research Institute, University of Cambridge, Cambridge CB2 1ER, U.K.)

\section{ABSTRACT}

The use of many display techniques for remotely sensed glaciological data requires the reduction of the data to a regularly spaced rectangular grid of values. Most remotely sensed data are not immediately suitable for display, because the area of interest is covered by more than one set of data on mutually incompatible grids (e.g. Landsat, AVHRR), or because the data are available as profiles along widely spaced ground tracks (e.g. radio echo-sounding, satellite altimetry). In addition, data may be sparsely and randomly scattered (e.g. surface elevations from TWERLE balloons).

A variety of techniques is available to reduce data to a specified grid system. These include spatial averaging, interpolation from nearest neighbours, and surface-fitting techniques, notably polynomial fitting and bi-cubic splines. All of these are useful under differing circumstances. 